\title{
Verification of the initial setup of experimental device compared to the FEM model
}

\author{
Lukáš Kapolka ${ }^{1, *}$, Lenka Štulerová ${ }^{1}$, and Stanislav Kmet ${ }^{1}$ \\ ${ }^{1}$ Faculty of Civil Engineering, Institute of Structural Engineering, Vysokoškolská 4, 04200 Košice, \\ Slovakia
}

\begin{abstract}
This paper compares and verifies the experimental membrane device with the model created in FEM software. At first, the experimental device needs to be properly set up and prepared. This includes settings of all input factors such as the placement of the technical fabric, the pretensioning of the edge ropes, the functionality of the actuators or load cells placed on the anchor rods. The numerical model in FEM software was created to confirm the functionality of the experimental device. Based on the results obtained by simple load cells measurements and the load results in the numerical model, it was confirmed that the behaviour of the experimental device coincided with the assumed behaviour of the membrane structure.
\end{abstract}

\section{Introduction}

Over the last century, major developments are happening in almost every part of industry. This occurs in areas such as information technology, medicine and the transport industry. The requirements for creating innovative technologies inseparably affect the civil engineering itself. This is reflected in the demand for new technical and technological processes, the development of hybrid types of structures or the introduction of new types of materials. Environmental and economic considerations are essential.

In particular, experimental research and development centres try to respond flexibly to this need for development and requirements. This implies that a wide range of different investigations, experiments and tests must be carried out to ensure the complete stability and safety of any structure before introducing new one into construction practice. The aim is to simulate a lot of different situations and conditions that can lead to unfavourable conditions and consequently affect the specimen in the worst possible way. However, such processes require a lot of time and effort, space and equipment, and last but not least, the need to ensure sufficient capacities of various experts and specialists [1].

In the construction industry, development can be carried out by creating so-called adaptive constructions. By this we can image constructions which can adapt to different conditions. This means that they can change their shape or position to positively influence their use. The aim is to reduce negatives optimally and maximize their positive properties and advantages, thus creating efficient units. Based on these characteristics, the life-cycle is

\footnotetext{
*Corresponding author: lukas.kapolka@tuke.sk
} 
prolonged and, as a result, more economically advantageous building constructions are realized [2].

For example, adaptive constructions include structural membranes. These are constructions made of technical textiles, which are very light but sufficiently durable even without the need for intermediate supports. Membrane constructions only work in tension and their specification is to find the correct prestressed shape called form-finding.

\section{FEM model}

Any research consists of 2 phases. The first is a numerical model and the second is measurements on an experimental device. In this case, the model in the Fig. 1 is created in the structural analysis software RFEM Dlubal and add-on module FF-Form-Finding.

This module determines equilibrium shapes of membrane and cable elements in RFEM. In this calculation process, the program searches for such a geometric position in which the surface stress/prestress of membranes and cables is in equilibrium with natural and geometric boundary conditions. By activating the FF option, the program always starts the form-finding process before the pure structural calculation of internal forces, deformation, etc., and generates a corresponding prestressed model for further analysis [3].

While defining a model of lightweight structures, you might realize the geometric position of the membranes and ropes is unclear. It is exactly the task of the FF process to find this position and fixate it. In the first instance, RFEM requires the initial input of the FF - elements [3].

The initial input requires a determination of surface stress value in the warp and weft direction of the membranes and the prestress level or sag dimension of the cable elements that should act according to the FF calculation. After a successful meshing, the program starts the FF process. This process adopts the mesh geometry and surface stress/prestress initially entered, and displaces the position of the mesh elements until the surface stress on the FE element is in equilibrium with the boundary conditions. The description of the surface stress on the membrane mesh elements can be defined in two ways (the tension method and the projection method). The step of displacement is performed iteratively according to the Update Reference Strategy (URS) method [3].

The URS method overcomes the difficulty by a rigorous algorithm that is based on differential geometry, continuum mechanics and numerical continuation. The method can be applied to the form finding of membranes and cable structures using any finite element discretization scheme, e.g. two-, three- or four-node elements or even elements of higher order. The method is stable and gives reliable results for physically reasonable combinations of pre-stress distribution and boundary conditions. The governing equation of minimal surface of form-finding can be written as [4]:

$$
\delta a=\int_{A} \delta(\operatorname{det} \mathbf{F}) \mathrm{d} A=\int_{A} \operatorname{det} \mathbf{F F}^{-\mathrm{T}}: \delta \mathbf{F} \mathrm{d} A=0
$$

where is :

$\delta a$ - the variaton of the surface

A - fixed reference area

$\mathrm{F}$ - deformaton gradient

The shape of this numerical model of hyperbolic paraboloid has $2 \times 2 \mathrm{~m}$ ground plan. The resulting geometry of the membrane has an overhang equal to the rise and it is $0.5 \mathrm{~m}$, which ultimately determines the overall height of the membrane per $1 \mathrm{~m} \mathrm{[4].}$

The membrane is modelled as a planar element, specifically 2 separate planar elements triangles, with a common edge connecting the lower anchor rods and third vertices at the 
upper anchorage points. The membrane thickness is $0.56 \mathrm{~mm}$ and is an orthotropic material. The technical fabric characteristics are specified by the manufacturer as follows: the modulus of elasticity in the warp direction is $E_{x}=1057 \mathrm{MPa}$, in the weft direction the elastic modulus $\mathrm{E}_{\mathrm{y}}=612 \mathrm{MPa}$. The values of Poisson's constant also change. In the main direction, it is $v_{\mathrm{xy}}=1.01$, in the other direction $v_{\mathrm{yx}}=0.58$. The last important feature is a shear module with a value $\mathrm{G}_{\mathrm{xy}}=240 \mathrm{MPa}$. The only one chosen feature within the model is a membrane prestress defined by value $4 \mathrm{kN} / \mathrm{m}$.

In order for the membrane structure to fulfil its role, it has to be stabilized in some way. For this case, edge ropes were used on all 4 sides of the membrane structure. These are simulated by rope elements with a diameter of $8 \mathrm{~mm}$. These are stainless steel elements with elastic modulus $\mathrm{E}_{\mathrm{L}}=130 \mathrm{GPa}$ and Poisson constant is $v=0.3$. As with the membrane, it is necessary to define the prestressing. In this case, the prestressing is set in the form of absolute sag of $0.2 \mathrm{~m}$.

Anchoring is also an important part of the numerical model. The experimental device is anchored with 2 anchor rods and 2 actuators. All these truss elements are rod sections made of S235 steel. One anchor rod is located in the lower right corner at the bottom, the other one is located at the top left along the same side. Both are modelled with $46 \mathrm{~mm}$ crosssections. Actuators are anchor rods that can change their length. They consist of $46 \mathrm{~mm}$ and $145 \mathrm{~mm}$ diameter rods simulating the real distribution of the actuator masses.

Last but not least, the steel frame is part of the computing model. The axial dimensions are $3.34 \times 3.34 \times 2.5 \mathrm{~m}$. It is a welded spatial structure consisting of rectangular hollow sections (RHS) and square hollow sections (SHS) profiles made of S235 steel. The essential profiles are SHS160x160x8 as columns, peripheral beams RHS140x140x8 and both base sides are reinforced with the same SHS140x140x 8 sections. The entire steel frame is then supported by 4 nodal hinge supports [5].

Projected model of membrane is loaded by the free circular area loading acting in global coordinate system on projection. At the beginning 6 load cases were created, when the applied force varied from 0 to $5 \mathrm{kN}$. The first state at force $\mathrm{F}=0 \mathrm{kN}$ represents the structure after form-finding with the influence of dead-weight.

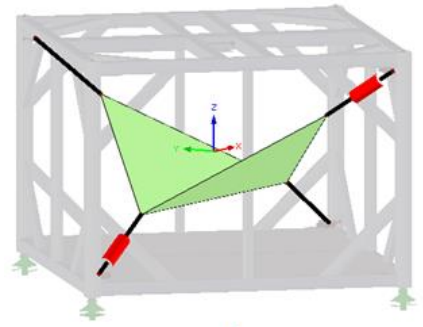

a.)

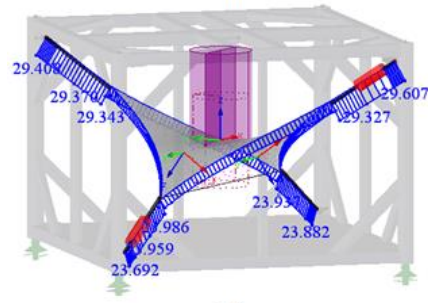

c.)

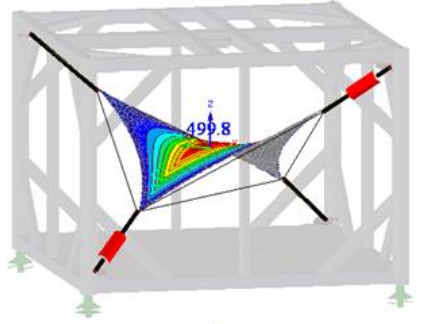

b.)

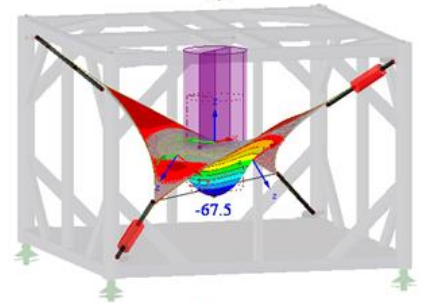

d.)

Fig. 1. a) membrane before form-finding; b) membrane after form-finding; c) internal forces in anchor rods and actuators $(F=5 \mathrm{kN})$; d deformation of membrane surface $(\mathrm{F}=5 \mathrm{kN})$. 


\section{Experimental device}

On the basis of theoretical assumptions and computational models created in the preliminary phase of the experiment, the shape of the adaptive hypar was chosen as the most suitable variant (Fig. 2). It is $2 \times 2 \mathrm{~m}$ membrane device with a total height of $1 \mathrm{~m}$, with $8 \mathrm{~mm}$ diameter stainless steel ropes located in the sleeves and anchored to the steel frame by 2 action elements and 2 anchor rods.

All the characteristics typical for this experimental device on the basis of the data provided by the manufacturer have been incorporated in the computational software mentioned above. The membrane is of Serge Ferrari Précontraint 502 type and is a polyester fabric with PVC coating. The membrane is woven in the directions of the individual vertices and is positioned within the device such that the $\mathrm{x}$-axis direction having the modulus of elasticity $\mathrm{E}_{\mathrm{x}}=1057 \mathrm{MPa}$ is anchored between the upper anchor rods (actuator AP2 and the rod T2).

Edge ropes are spiral strand with open construction $1 \times 19(1+6+12)$ and nominal strength $1570 \mathrm{MPa}$. The membrane is anchored to the steel frame from Inova through hinged anchor rods or actuators with load cells, anchor plates and rope ends. The membrane is loaded by a load piston and a seat that follows the membrane shape and is located in geometric centre of the frame [6].

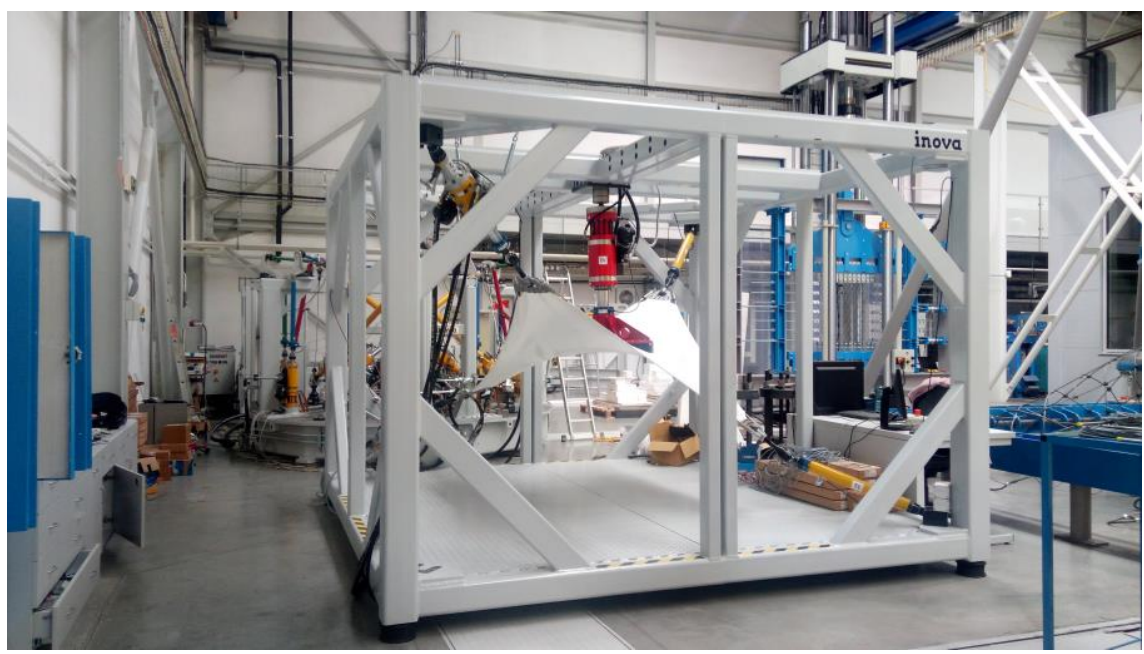

Fig. 2. The experimental device in a laboratory.

\section{Loading, results and comparison}

Loading of experimental device was performed in 3 series and measurement was recorded on all of 4 anchors, the results being considered as the arithmetic mean of these measurements.

The anchor rod T1 is located at the bottom right, the rod T2 is located at the top right of the device. The actuator element AP1 is located on the lower left, AP2 is located on the upper left (Fig. 2). Before loading, the load piston had to be levelled (Fig. 3).

In each series, the structure was loaded with 6 different load cases. At the beginning of any measurement, the membrane must be pretensioned at $22.2 \mathrm{kN}$ in load cells on the anchor rods, which is a form-finding process and form-finding force. In this state, when the structure is loaded with load piston force $\mathrm{F}=0 \mathrm{kN}$, the first force measurement in load cells on anchor rods was made (Fig. 4) 
The series of measurements was further supplemented by a gradual loading with an increase of $1 \mathrm{kN}$ up to $5 \mathrm{kN}$. At each load, the load values on the load cells (Table 1) and the membrane deflection caused by shifts of the load piston were read (Fig. 5, Table 3). An average value is then calculated from all of these series, which is ultimately compared with the values obtained in the computational software (Table 2). It should be noted that every reading of the results was made 1 minute after the load has stabilized.

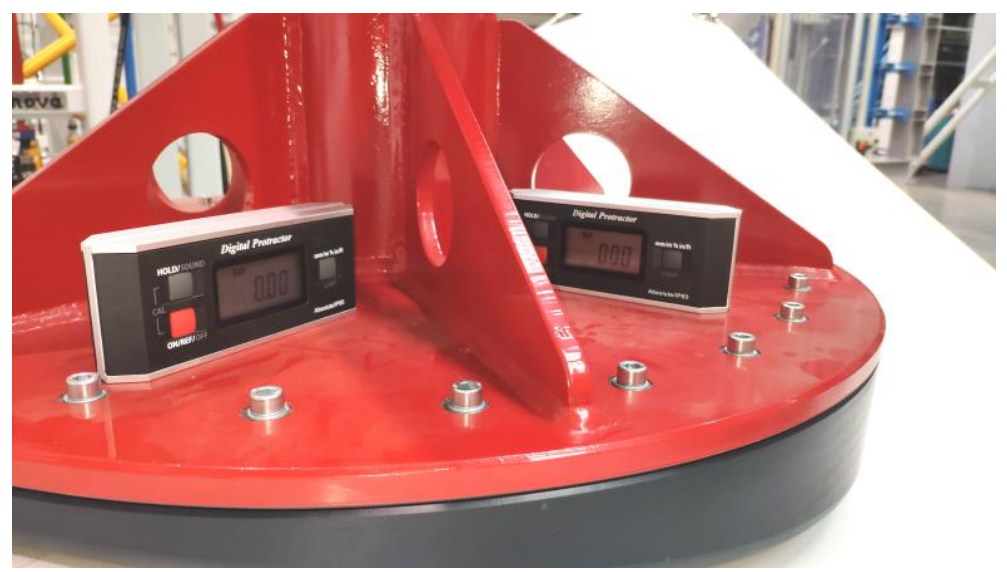

Fig. 3. Levelling the load piston.

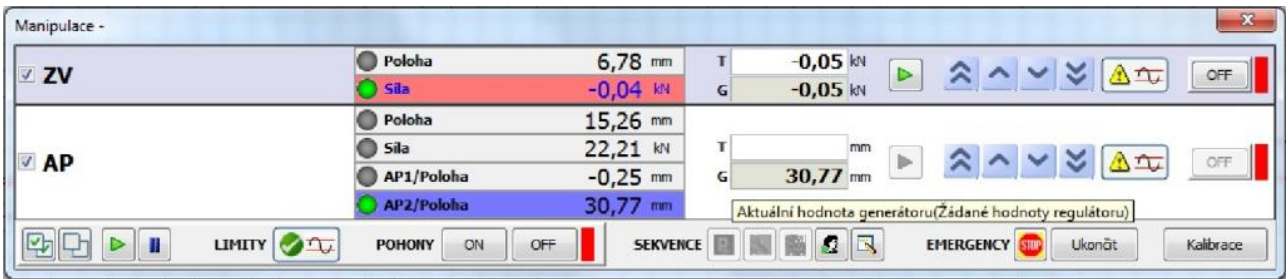

Fig. 4. Results from the experimental device software, when $F=0 \mathrm{kN}$.

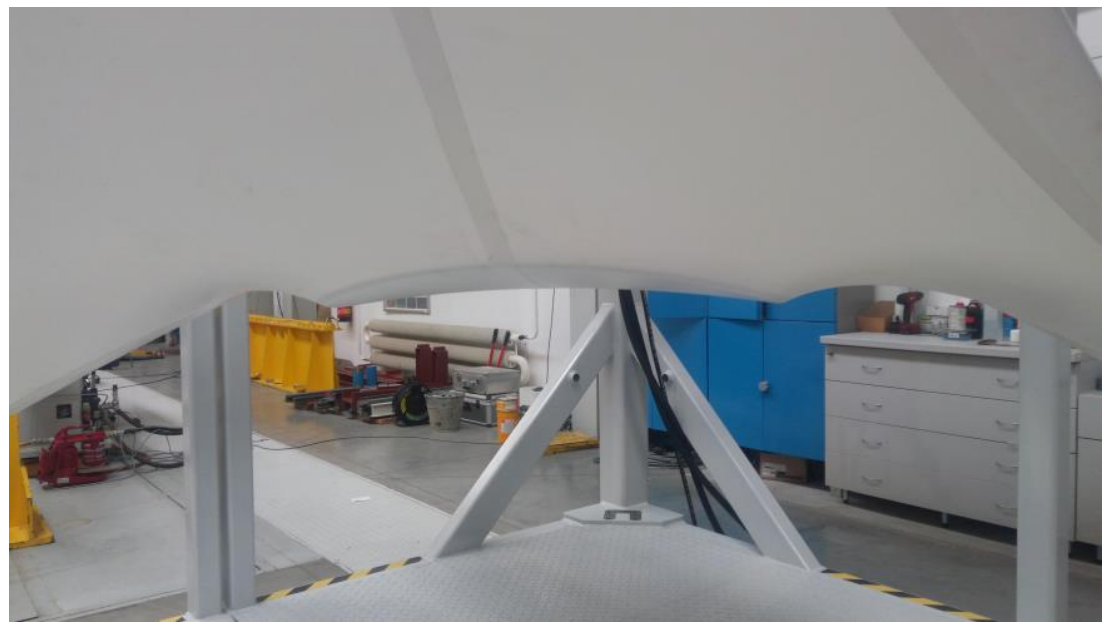

Fig. 5. Real deformation on the device (load $5 \mathrm{kN})$. 
Table 1. 3 sets of loading and their average value.

\begin{tabular}{|c|c|c|c|c|c|}
\hline $\begin{array}{c}\mathrm{F} \\
(\mathrm{kN})\end{array}$ & $\begin{array}{c}\text { Anchor } \\
\text { label }\end{array}$ & $\begin{array}{l}\text { 1. serie } \\
\mathrm{N}(\mathrm{kN})\end{array}$ & $\begin{array}{l}\text { 2. serie } \\
\mathrm{N}(\mathrm{kN})\end{array}$ & $\begin{array}{l}\text { 3. serie } \\
\mathrm{N}(\mathrm{kN}) \\
\end{array}$ & $\begin{array}{l}\mathrm{N}_{\mathrm{avg}} \\
(\mathrm{kN})\end{array}$ \\
\hline \multirow{4}{*}{0} & AP1 & 22.30 & 22.49 & 22.57 & 22.453 \\
\hline & T1 & 22.06 & 22.27 & 22.35 & 22.227 \\
\hline & AP2 & 22.29 & 22.50 & 22.60 & 22.463 \\
\hline & $\mathrm{T} 2$ & 22.20 & 22.36 & 22.45 & 22.337 \\
\hline \multirow{4}{*}{1} & AP1 & 21.90 & 22.13 & 22.20 & 22.077 \\
\hline & T1 & 21.68 & 21.93 & 21.97 & 21.860 \\
\hline & AP2 & 22.93 & 23.19 & 23.23 & 23.117 \\
\hline & $\mathrm{T} 2$ & 22.86 & 23.06 & 23.11 & 23.010 \\
\hline \multirow{4}{*}{2} & AP1 & 21.65 & 22.05 & 22.14 & 21.947 \\
\hline & $\mathrm{T} 1$ & 21.46 & 21.88 & 21.95 & 21.763 \\
\hline & AP2 & 23.73 & 24.16 & 24.22 & 24.037 \\
\hline & $\mathrm{T} 2$ & 23.68 & 24.04 & 24.12 & 23.947 \\
\hline \multirow{4}{*}{3} & AP1 & 21.60 & 22.11 & 22.22 & 21.977 \\
\hline & $\mathrm{T} 1$ & 21.44 & 21.97 & 22.05 & 21.820 \\
\hline & AP2 & 24.72 & 25.25 & 25.33 & 25.100 \\
\hline & $\mathrm{T} 2$ & 24.67 & 25.13 & 25.22 & 25.007 \\
\hline \multirow{4}{*}{4} & AP1 & 21.59 & 22.23 & 22.41 & 22.077 \\
\hline & $\mathrm{T} 1$ & 21.45 & 22.11 & 22.27 & 21.943 \\
\hline & AP2 & 25.71 & 26.37 & 26.54 & 26.207 \\
\hline & $\mathrm{T} 2$ & 25.62 & 26.26 & 26.42 & 26.100 \\
\hline \multirow{4}{*}{5} & AP1 & 21.63 & 22.39 & 22.56 & 22.193 \\
\hline & $\mathrm{T} 1$ & 21.52 & 22.29 & 22.43 & 22.080 \\
\hline & AP2 & 26.73 & 27.54 & 27.67 & 27.313 \\
\hline & $\mathrm{T} 2$ & 26.66 & 27.38 & 27.54 & 27.193 \\
\hline
\end{tabular}


Table 2. Comparison of force in FEM model with experiment and their difference.

\begin{tabular}{|c|c|c|c|c|c|c|}
\hline $\begin{array}{c}\mathrm{F} \\
(\mathrm{kN})\end{array}$ & $\begin{array}{c}\text { Anchor } \\
\text { label }\end{array}$ & $\begin{array}{c}\mathrm{FEM} \\
\text { model } \\
\mathrm{N}(\mathrm{kN})\end{array}$ & $\begin{array}{c}\text { ED } \\
\mathrm{N}(\mathrm{kN})\end{array}$ & $\Delta(\mathrm{kN})$ & $\Delta_{\mathrm{r}}(\%)$ & $\begin{array}{l}\Delta_{\text {all }} \\
(\%)\end{array}$ \\
\hline \multirow{4}{*}{0} & AP1 & 22.112 & 22.453 & 0.341 & 1.520 & \multirow{4}{*}{0.877} \\
\hline & $\mathrm{T} 1$ & 22.064 & 22.227 & 0.163 & 0.732 & \\
\hline & AP2 & 22.237 & 22.463 & 0.226 & 1.008 & \\
\hline & $\mathrm{T} 2$ & 22.281 & 22.337 & 0.056 & 0.249 & \\
\hline \multirow{4}{*}{1} & AP1 & 22.112 & 22.077 & -0.035 & -0.160 & \multirow{4}{*}{-0.843} \\
\hline & T1 & 22.064 & 21.860 & -0.204 & -0.933 & \\
\hline & AP2 & 23.304 & 23.117 & -0.187 & -0.810 & \\
\hline & $\mathrm{T} 2$ & 23.348 & 23.010 & -0.338 & -1.469 & \\
\hline \multirow{4}{*}{2} & AP1 & 22.460 & 21.947 & -0.513 & -2.339 & \multirow{4}{*}{-2.863} \\
\hline & T1 & 22.411 & 21.763 & -0.648 & -2.976 & \\
\hline & AP2 & 24.706 & 24.037 & -0.669 & -2.785 & \\
\hline & $\mathrm{T} 2$ & 24.749 & 23.947 & -0.802 & -3.351 & \\
\hline \multirow{4}{*}{3} & AP1 & 22.948 & 21.977 & -0.971 & -4.420 & \multirow{4}{*}{-4.735} \\
\hline & T1 & 22.899 & 21.820 & -1.079 & -4.945 & \\
\hline & AP2 & 26.231 & 25.100 & -1.131 & -4.506 & \\
\hline & $\mathrm{T} 2$ & 26.274 & 25.007 & -1.267 & -5.068 & \\
\hline \multirow{4}{*}{4} & AP1 & 23.480 & 22.077 & -1.403 & -6.357 & \multirow{4}{*}{-6.443} \\
\hline & $\mathrm{T} 1$ & 23.430 & 21.943 & -1.487 & -6.775 & \\
\hline & AP2 & 27.785 & 26.207 & -1.578 & -6.023 & \\
\hline & $\mathrm{T} 2$ & 27.827 & 26.100 & -1.727 & -6.617 & \\
\hline \multirow{4}{*}{5} & AP1 & 24.017 & 22.193 & -1.824 & -8.217 & \multirow{4}{*}{-8.042} \\
\hline & $\mathrm{T} 1$ & 23.968 & 22.080 & -1.888 & -8.551 & \\
\hline & AP2 & 29.330 & 27.313 & -2.017 & -7.383 & \\
\hline & T2 & 29.373 & 27.193 & -2.180 & -8.015 & \\
\hline
\end{tabular}


Table 3. Comparison of surface deformation in FEM model with experiment and their difference.

\begin{tabular}{|c|c|c|c|c|c|}
\hline Set & $\begin{array}{c}\mathrm{F} \\
(\mathrm{kN})\end{array}$ & $\begin{array}{c}\text { FEM } \\
\text { model } \\
\mathrm{u}(\mathrm{mm})\end{array}$ & $\begin{array}{c}\text { LP } \\
\mathrm{u}(\mathrm{mm})\end{array}$ & $\Delta(\mathrm{kN})$ & $\Delta(\%)$ \\
\hline \multirow{6}{*}{$\begin{array}{c}1 . \\
\text { sada }\end{array}$} & 0 & 0.0 & 0.00 & 0.00 & - \\
\hline & 1 & 18.6 & 14.04 & -4.56 & -32.48 \\
\hline & 2 & 34.2 & 25.72 & -8.48 & -32.97 \\
\hline & 3 & 47.0 & 36.69 & -10.31 & -28.10 \\
\hline & 4 & 57.9 & 48.19 & -9.71 & -20.15 \\
\hline & 5 & 67.4 & 59.20 & -8.20 & -13.85 \\
\hline \multirow{6}{*}{$\begin{array}{c}2 . \\
\text { sada }\end{array}$} & 0 & 0.0 & 0.00 & 0.00 & - \\
\hline & 1 & 18.6 & 14.97 & -3.63 & -24.25 \\
\hline & 2 & 34.2 & 26.44 & -7.76 & -29.35 \\
\hline & 3 & 47.0 & 36.90 & -10.10 & -27.37 \\
\hline & 4 & 57.9 & 46.71 & -11.19 & -23.96 \\
\hline & 5 & 67.4 & 56.59 & -10.81 & -19.10 \\
\hline \multirow{6}{*}{$\begin{array}{c}3 . \\
\text { sada }\end{array}$} & 0 & 0.0 & 0.00 & 0.00 & - \\
\hline & 1 & 18.6 & 15.23 & -3.37 & -22.13 \\
\hline & 2 & 34.2 & 26.95 & -7.25 & -26.90 \\
\hline & 3 & 47.0 & 37.63 & -9.37 & -24.90 \\
\hline & 4 & 57.9 & 47.17 & -10.73 & -22.75 \\
\hline & 5 & 67.4 & 56.43 & -10.97 & -19.44 \\
\hline
\end{tabular}

Based on the processed results, the following can be mentioned: As the series progresses, the accuracy of individual force measurements increases compared to the model. The value of deviation changes in the $1^{\text {st }}$ set of measurements to the maximum $10.579 \%$ in compare to experimental device, in the $2^{\text {nd }}$ set the maximum is $7.143 \%$, for the last set maximal deviation from numerical model is $6.493 \%$. These values are obtained at the highest load. If the load increases, the deviation increases too. Maximal average deviation under load is at force $\mathrm{F}=5 \mathrm{kN}$ with a value of $8.042 \%$, which can be considered a reasonably acceptable value in such a non-linear system.

The problem arises when comparing surface deformation values. Here, there is a maximal deviation up to $32.97 \%$ at $1^{\text {st }}$ set at $2 \mathrm{kN}$ force. As the force increases, the deviation decreases, within the individual sets the deviation gradually decreases. Minimal value of deviation is at the $1^{\text {st }}$ set of measurement, at maximal force $\mathrm{F}=5 \mathrm{kN}, 13.851 \%$. 


\section{Conclusion}

As already mentioned, the differences in the values of the forces measured on the experimental device and in the numerical model represent maximum difference of $8,042 \%$, which is an acceptable value, and so we can say that the implemented equipment coincides with the theoretical model in terms of behaviour.

However, there are large unacceptable differences when comparing membrane deformations and displacement of the load piston. We can say that based on these results, the real construction acts more rigidly than the computational model, which is more appropriate in terms of safety. Because the deformation is mainly a result of material characteristics, it is assumed that the resulting differences are mainly due to the material characteristics specified by the manufacturer, which may not coincide with real characteristics. To correct this problem, it is needed to carry out material tests on orthotropic membrane samples to approximate the real behaviour and results on the experimental device.

Similarly, the fact that the technical fabric as a planar element must follow the spatial shape of the hyperbolic paraboloid can also have a significant impact on the results. This is accomplished by joining 2 parts at the membrane seat. This connection is made by a welded seam, and thus a local line duplication of material occurs, which may subsequently lead to an increase in the stiffness of the structure in the vertical direction when measuring the deformation.

This work was supported by The Slovak Scientific Grant Agency under the contract No. VEGA $1 / 0302 / 16$.

\section{References}

1. D.S. Wakefield, Engineering Structures, Engineering analysis of tension structures: theory and practice, 21, 680-690, (1999)

2. S. Kmet', Building materials, Modern cable and membrane constructions, 8, 48-52, (2012) - ISSN 1336-7617

3. Dlubal: Form-Finding in RFEM. Available: <https://www.dlubal.com/en/support-and-learning/support/knowledge-base/001391>

4. R. Wüchner, K.-U. Bletzinger, Int. J. Numer. Meth. Engng., Stress-adapted numerical form finding of pre-stressed surfaces by the updated reference strategy, 64, 143-166, (2005)

5. L. Kapolka, L. Štulerová, S. Kmet', Assembly of steel constructions workers, Adaptive membrane structure - experimental device, 44, (2019)

6. INOVA Prague s.r.o.: Documentation of experimental device - 17120 part 1 Membrane machine, Prague, (2017) 